\title{
Glutathione S-Transferases of 28kDa as Major Vaccine Candidates against Schistosomiasis
}

\section{Gilles Riveau/ ${ }^{+}$, Odile Poulain-Godefroy, Loïc Dupré, Franck Remoué, Nathalie Mielcarek, Camille Locht*, André Capron}

\author{
Relations Hôte-Parasite et Stratégies Vaccinales, Inserm U167 *Laboratoire de Microbiologie Génétique et \\ Moléculaire, Inserm U477, Institut Pasteur de Lille, 1 rue du Professeur A. Calmette, BP245, 59019 \\ Lille Cedex, France
}

For the development of vaccine strategies to generate efficient protection against chronic infections such as parasitic diseases, and more precisely schistosomiasis, controlling pathology could be more relevant than controlling the infection itself. Such strategies, motivated by the need for a cost-effective complement to existing control measures, should focus on parasite molecules involved in fecundity, because in metazoan parasite infections pathology is usually linked to the output of viable eggs. In numerous animal models, vaccination with glutathione S-transferases of $28 \mathrm{kDa}$ has been shown to generate an immune response strongly limiting the worm fecundity, in addition to the reduction of the parasite burden. Recent data on acquired immunity directed to 28GST in infected human populations, and new development to draw adapted vaccine formulations, are presented.

Key words: schistosomiasis- 28GST - vaccine - immune response - live vectors - nucleic acid vaccine

Considered in terms of biological features most relevant to immunology, the life cycle of schistosomes offers a series of events that promote a close interaction between the parasite and the immune system: active cutaneous penetration of larvae and their transformation into schistosomula with a pulmonary stage of maturation, a complex migratory cycle in the vertebrate host, intravascular localization and blood feeding of adult worms, egg deposition in mucosae, liver, and various tissues, and prolonged survival in immune vertebrate hosts. These prominent characters of a vertebrate infection have elicited extensive immunological research in three major areas: effector mechanisms of resistance; immune mechanisms of pathogenesis; mechanisms of parasite survival and regulation of host immune system. In each of these research areas, novel mechanisms have been uncovered, leading to more general concepts bearing implications far beyond the specific field of schis-

\footnotetext{
This work was supported by European Economic Community contracts IC18CT95-0013 and BIO4CT96-0374, the Institut Pasteur de Lille, the Région Nord-Pas-DeCalais, and INSERM. LD holds a fellowship from the Institut Pasteur de Lille, and FR and NM hold fellowships of the Région Nord-Pas-De-Calais.

${ }^{+}$Corresponding author. Fax: $+33-3-20877888$. E.mail: gilles.riveau@pasteur-lille.fr

Received 4 May 1998

Accepted 31 August 1998
}

tosomiasis. From rodent models to man, these studies have allowed promising approaches towards the possible immunological control of one of the major human parasitic diseases, by pointing to which schistosome antigen may induce protection and which component of the immune response should be elicited by the immunization schedule. In addition to these major aims, one of the objectives is to generate appropriate vaccine formulations with respect to the selected antigen(s), the nature of the immune response required, and properties for easy use in the field. The ideal vaccine formulation, which would avoid needles, multiple administrations, and cold chain, is still to be elaborated. However, the recent advances in vaccine biotechnology brought us new knowledge on the mucosal associated immune system, chemistry of lipids and polymers, and molecular biology, allowing us to generate vectors which would be the basis of new generation vaccines dedicated to infected population from developing countries.

\section{NEW ADVANCES IN RESEARCH ON 28GSTS AS EXPERIMENTAL CANDIDATE VACCINES AND ANTIGENIC TARGETS IN INFECTED HUMAN POPULATIONS}

The $28 \mathrm{kDa}$ glutathione S-transferase of Schistosoma mansoni (Sm28GST) could be considered today as the best characterized (molecular cloning, full sequence of the chromosomal gene (McNair et al. 1993) and crystallisation (Trottein et al. 1992b) and the most tested vaccine candidate antigen. The protective properties of this molecule have stimulated work both on the GSTs of 
other schistosome species and on other enzymes involved in detoxification and antioxidant pathways.

Schistosome GSTs were first identified as potential targets of protective immunity by two separate approaches. The identification of a $28 \mathrm{kDa}$ fraction of soluble $S$. mansoni adult worm antigens that elicits a protective antibody response and confers a high degree of protection to both rats and mice (Balloul et al. 1985) was followed by the cloning of the cDNA encoding the major antigenic component of the fraction (Balloul et al. 1987a) which was identified as a GST (Taylor et al. 1988). Sm28GST was expressed in both Escherichia coli and in yeast in an enzymatically active form that allows its purification by affinity chromatography on glutathione-agarose (Taylor et al. 1988). The recombinant protein elicits protective immunity in rats, hamsters (Balloul et al. 1987a, Grezel et al. 1993), baboons (Balloul et al. 1987b) and in mice (Boulanger et al. 1991, Xu et al. 1993, Pancré et al. 1994). The level of protection conferred against infection varies from a mean of $50-70 \%$ in rats to $40-50 \%$ in mice and $40 \%$ in baboons. The relevance of our choice for the 28GST as vaccine candidate has been strengthened by vaccination experiments performed in Sudan against cattle schistosomiasis due to $S$. bovis (Bouchara et al. 1993).

General discussions of immune protection against schistosome infection have concerned a reduction in the numbers of parasites recovered from immunized animals compared to non-immunized controls. The experiments in baboons using recombinant Sm28GST highlighted a different protective effect of immunization, which until recently had not been demonstrated with any other antigen. This effect was a reduction in the fecundity of female worms reflected in a reduced excretion of eggs by immunized animals, and a reduction in tissue egg loads in mice immunized with Sm28GST and challenged with $S$. mansoni (Boulanger et al. 1991) and in cattle immunized with native Sb28GST and infected with S. bovis (Bouchara et al. 1993). This particular protective effect of the immune response could be related to the inhibition of the GST enzymatic activity by antibodies (Xu et al. 1991, Grzych et al. 1993), which is vital to the survival of the parasite in the definitive host (Mitchell 1989). Thus, these findings open new and accessible concepts in vaccine research against schistosomiasis, dedicated to the reduction of the parasite fecundity, more in terms of anti-pathological vaccines than in terms of eradication of the parasitic disease in the definitive host. Indeed, a vaccine, aimed at preventing the development of the serious forms of the disease, has therefore become a major goal for applied research, reinforced by the recent emergence of schistosome strains naturally resistant to chemotherapy (Ismail et al. 1994, Fallon et al. 1996).

The logistic benefit of the availability of a polyvalent vaccine against several schistosome species infecting the same definitive host prompted researchers to use primate and cattle models to investigate the capacity of GSTs in Freund Complete Adjuvant to prevent heterologous experimental infections. The efficacy of patas monkey immunization with 28GST cloned from S. mansoni to prevent the deleterious impact of an experimental challenge with S. haematobium was evaluated in Niger (Boulanger et al. 1995). A marked anti-fecundity effect and an alleviation of the bladder pathology were recorded in the vaccinated patas monkeys, showing the major antigenic properties of some of the conserved epitopes of $28 \mathrm{kDa}$ GSTs in both schistosome strains. In parallel, the protective efficacy of cattle immunization with the cloned $S$. bovis 28GST against a natural $S$. mattheei challenge, was tested in Zambia (De Bont et al. 1997). In addition to the spectacular reduction of egg output $(>80 \%)$, a dramatic reduction of miracidia viability was observed, showing that the recombinant Sb28GST can provide significant protection against natural infection by $S$. mattheei.

These demonstrations open the possibility that a cross-specific anti-fecundity vaccine might be achieved, as far as 28GSTs of the concerned species would present highly conserved domains involved in the catalytic activity of the antigens, as it has been described for the $\mathrm{N}$ and $\mathrm{C}$ terminal domains (respectively AA 10-43 and AA 190-211) of the 28GSTs from S. mansoni and S. haematobium (Trottein et al. 1992a).

The relevance of the induction of humoral immune response against specific domains of the 28GST was pointed out by the study of the immune status of infected human populations. A correlation could be observed between the production of IgA Abs directed against the peptides involved in the GST catalytic site and the resistance to reinfection (Auriault et al. 1990, Grzych et al. 1993). Moreover, the human IgE response to one of the major B epitopes of the Sm28GST (AA 115131) could be involved in the reduction of worm burden through an antibody-dependent cell cytotoxicity mechanisms.

The dramatic emergence of a new focus (1989) of $S$. mansoni infection in the Senegal river basin provides a unique opportunity to study the acquired humoral immune response before any chemotherapy treatment, and to confirm the hypothesis of multifactorial mechanisms involved in the protective effect of vaccination with 28GSTs. Very 
recently, we developed a study on specific immune profiles against Sm28GST in populations exempt of chemotherapy and living in this area where the prevalence reaches almost $100 \%$. Sera from 185 infected individuals were collected, and the specific antibody profile to the protective antigen was evaluated according to the age and to the intensity of infection (EPG). In addition, recognition of major epitopes of the Sm28GST by antibodies and their capacity to inhibit the enzymatic activity of the protein were assessed. Specific IgE directed to 115-131 sequence peptide raised at the early age, when the EPG number decreased. In addition, we showed that high specific IgG3 and IgA Ab levels were closely associated with low EPG counts in the whole population. The production of specific IgG3, and particularly of IgG3 Abs directed to the peptides corresponding to the catalytic site of the Sm28GST were associated with a low level of infection intensity followed by a peak of production of neutralising anti-Sm28GST IgA response. Surprisingly, the nature of the isotype involved in this age-dependent neutralising effect seems different according to the sex of individuals. Specific IgG3 production is strongly correlated to inhibition of Sm28GST activity in the male population, whereas anti-Sm28GST IgA Abs are predominantly associated with this effect in the female population (Remoué et al., unpub. data).

Thus, it appears that at least two distinct classes of immunological effectors may account for the two protective effects of 28GST vaccination, i.e. reduction of worm burden and reduction of the worm fecundity, both from the study of experimental models and of human populations. As could be expected, immunity to such complex organisms as schistosomes is obviously multifactorial in nature and there is no a priori reason to think that successful immunization against this pathogen can be achieved through the elicitation of a single effector mechanism.

NEW EXPERIMENTAL APPROACHES IN THE VACCINE STRATEGY AGAINST SCHISTOSOMIASIS USING 28GSTS

Considered as a whole, these observations and the confrontation of studies in experimental models and in infected humans point to a major message regarding the design of an anti-schistosome vaccine using 28GSTs. The concept of isotype selection which we have developed since 1976 appears as an essential factor for the expression of optimal resistance to reinfection. The dynamic balance in chronic schistosomiasis between effector and blocking antibody isotypes against the same molecule appears to account for the variable expression of immunity. Among effector antibody isotypes, $\operatorname{IgE}$ and $\operatorname{IgA}$ appear to act on different functional targets of the parasite. The optimal induction through immunization of the appropriate antibody isotypes is therefore of primary importance to the success of any vaccine strategy. However, our approach towards this goal is presently hampered by our limited knowledge of the immunological mechanisms driving isotype selection, and by empirical criteria in the choice of appropriate antigen delivery systems. The demonstration of the so far unsuspected function of IgA antibodies in schistosomiasis and their potential role in protective immunity has paved the way to new possibilities of immunization strategies through mucosal routes. Although success has been obtained with oral administration of Sm28GST entrapped into liposomes (Ivanoff et al. 1996, Phillips et al. 1996), our strategies have been recently driven to the use of the encoding gene instead of the recombinant protein. The two selected approaches were, on the one hand the production of recombinant bacteria expressing the GST, and on the other hand, the construction of naked DNA integrating the protein encoding gene for its use as nucleic acid vaccine (NAV).

Live vaccine vectors are usually very effective and generally elicit immune responses of higher magnitude and longer duration than non-living vectors. Although the majority of living vectors are given by the oral route, as we previously developed (Khan et al. 1994) we were the first to describe the construction of a bacterial vector designed to be delivered via the respiratory tract (Renauld-Mongenie et al. 1996). Bordetella pertussis, the etiologic agent of whooping cough colonises very efficiently the human respiratory tract. The filamentous hemagglutinin (FHA) is the major adhesin, with three distinct binding activities (Locht et al. 1993) and presents a high immunogenic potential. For these reasons, we fused the Sm28GST cDNA to the FHA gene. The recombinant $B$. pertussis was able to express the hybrid protein and has kept its ability of lung colonisation and autoagglutination. A single intranasal administration of the recombinant strain (BPGR60; 510 6 CFU in PBS instilled in the nostrils of 4-week-old female OF1 mice) was able to induce IgA and IgG antibodies against Sm28GST in the bronchoalveolar lavage fluids in mice (Renauld-Mongenie et al. 1996). Serum antibodies became detectable after either a boost with rSm28GST or an experimental infection given two months later (Mielcarek et al. 1997). The anti-Sm28GST isotype profile showed the presence of $\operatorname{IgG} 1, \operatorname{IgG} 2 \mathrm{a}$, and $\operatorname{IgG} 2 \mathrm{~b}$ as well as $\operatorname{IgA}$, suggesting a mixed Th1-Th2 response (Fig. 1). Wild type bacteria (BPSM) was used as a control. Using the same immunization protocol, mice were challenged for experimental infection (70 S. 


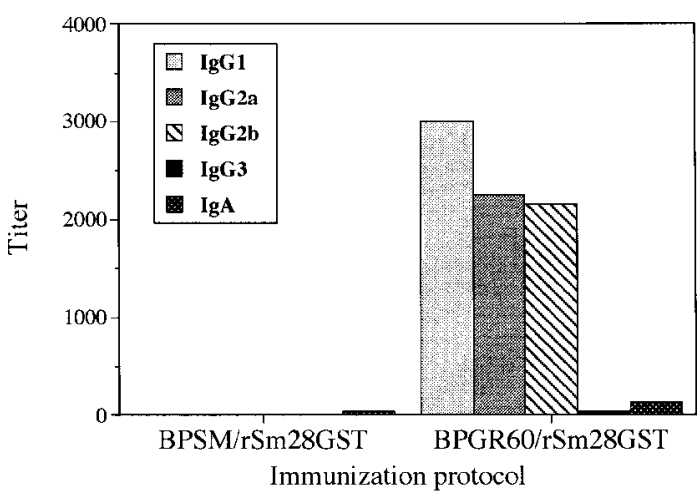

Fig. 1: antibody response after intranasal administration of recombinant Bordetella pertussis producing Sm28GST (BPGR60) - OF1 mice were intranasally immunized with $510^{6} \mathrm{CFU}$ of recombinant BPGR60 or wild-type BPSM and intranasally boosted two months later with $20 \mu \mathrm{g}$ of rSm28GST. The sera were collected 14 days later. The isotype distribution of the antibody response in the pooled serum was evaluated by ELISA (Mielcarek et al. 1997). Results were expressed in titers, reported as the reciprocal of the dilution giving on OD three times that of the conjugate control.

mansoni cercariae percutaneously) one week after the boost with rSm28GST. A significant reduction in worm burden (about 33\%) was obtained together with a significant reduction of the number of tissue eggs $(42 \%)$ in the group immunized with BPGR60 when compared to the group which has received only PBS (Fig. 2). When immunized with wild type $B$. pertussis, mice presented a small decrease in number of worms and tissue eggs which was not significant. In a purpose to make possible the use of this type of living vector in humans, we designed new strains deleted for virulence factors. Recent experiments indicated that a single nasal administration in mice with a particular recombinant detoxified strain was able to induce highly protective immune responses against both a $B$. pertussis infection and a parasite challenge (Mielcarek et al. 1998).

We also developed a recent approach of mucosal immunization using recombinant BCG. This live attenuated Mycobacterium bovis strain, is commonly used in many countries as a vaccine against human tuberculosis (Colditz et al. 1994). Both cellular and humoral immune responses are observed in animal models vaccinated with BCG (Ladel et al. 1995, Huygen et al. 1996). Therefore, this micro-organism constitutes an attractive live vector for the presentation of foreign antigens and recombinant expression systems have already been developed for antigen presentation (Stover et al. 1991). Bout et al. (1977) have already described the capacity of BCG to induce short-term resistance against $S$. mansoni. Recombinant BCG producing protective antigens, may combine this endogenous property with antigen-specific immunoprotection and may therefore represent a particularly attractive vaccine vehicle against schistosomiasis. Thus, we developed a rBCG strain expressing the Sm28GST under the control of hsp60 promoter (Kremer et al. 1996). Antigen specific IgG1, IgG2a, IgG2b, and IgA antibodies were

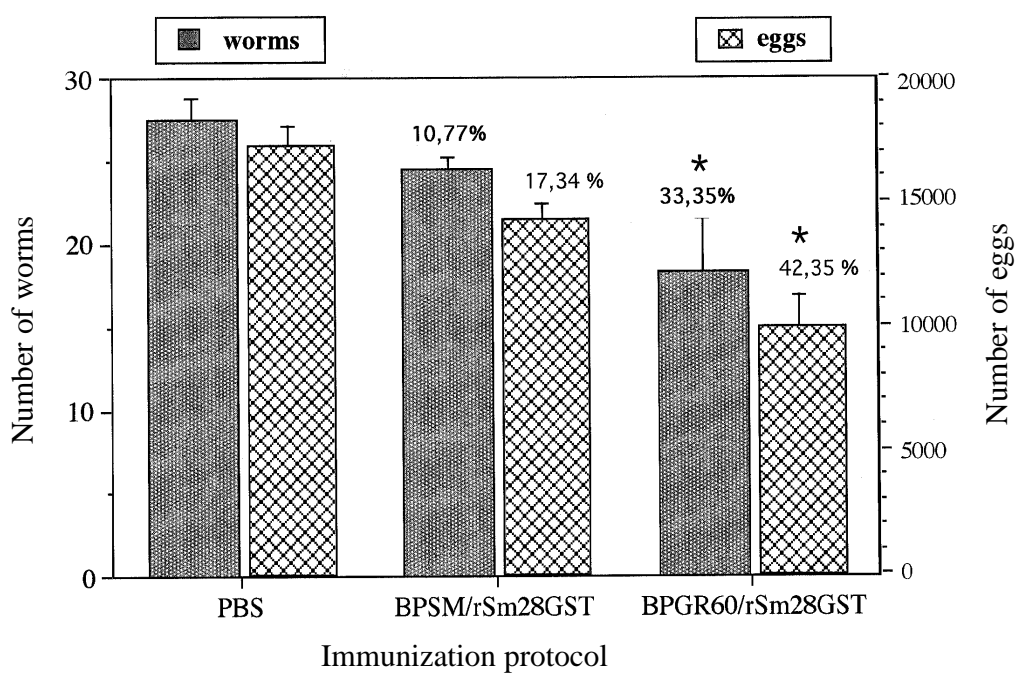

Fig. 2: protective effect of immunization with of recombinant Bordetella pertussis producing Sm28GST (BPGR60) against challenge with Schistosoma mansoni cercariae - OF1 mice were immunized as previously described (Fig. 1). Mice were infected with $70 \mathrm{~S}$. mansoni furcocercariae. The number of adult worms was determined by portal perfusion six weeks later. The percentage of protection is calculated by comparison with numbers of worms recovered from the control group. Egg charge is expressed for each mouse as the number of eggs per gram of intestine and liver combined. The percentage of reduction comparison with numbers of eggs recovered from the control group. *, significant at $\mathrm{P}<0.01$ (Student's $t$ test). 
elicited after a single administration by different routes, including the nasal route, in Balb/c mice. In addition, strong neutralization of the Sm28GST enzyme activity by these sera was obtained. This latter property of the induced immune response reinforces our aim to develop adapted recombinant live vectors against schistosomiasis for human use.

Genetic vaccination against schistosomiasis could represent a promising alternative to recombinant antigen vaccination since antigen-encoding plasmid DNA is very stable when compared to recombinant live vectors or even to the corresponding protein antigen and can be used without any adjuvant. This new approach to vaccination has proven to elicit both humoral and cellular responses specific to the plasmid encoded antigen and to be efficient in conferring protective immunity in a large number of viral and bacterial infectious disease models (Fynan et al. 1993, Ulmer et al. 1993, Lai et al. 1995, Wang et al. 1995, Huygen et al. 1996). Our approach consisted in the intradermal administration of plasmid DNA containing the fulllength Sm28GST cDNA sequence (Balloul et al. 1987a). The skin is the penetration site of the parasite where the invading schistosomula releases Sm28GST (Porchet et al. 1994). Furthermore the skin, comparable to some extends to mucosal tissues, presents a developed lymphoid system able to generate both local and systemic immunity. Furthermore, the participation of the skin associatedlymphoid system in protection against $S$. mansoni infection has been already reported (Mountford et al. 1992).

The Sm28GST expression plasmid, pNIp28, was constructed by PCR amplification of the full-length Sm28GST cDNA sequence and cloning into PCR II (TA cloning System, Invitrogen, San Diego, CA). Fischer rats were immunized by three intradermal injections of $200 \mu \mathrm{g}$ pNIp28 at 14 days intervals. Immuno-histochemical analysis of skin samples corresponding to both the plasmid injection site and distant sites were performed 2 days or 14 days after injection. The localisation of Sm28GST in the skin (in derm and muscle layer under the derm) was similar 2 days or 14 days after pNIp28 injection and was concentrated in a confined area where plasmids had been administered (Dupré et al. 1997). Levels of Sm28GST specific IgG of different isotypes were evaluated by ELISA on sera from pNIp28-immunized animals. Antibodies were detected in the sera of intradermally immunized animals as soon as 28 days after the first administration. The antibody response increased rapidly to a peak at day 42 and persisted at a constant level for at least 126 days (Fig. 3). The IgG antibody response against Sm28GST was exclusively constituted of IgG2a and IgG2b subclasses.
To evaluate the functionality of the induced anti-Sm28GST antibodies, in vitro ADCC assays were performed in the presence of immune sera using macrophages as effector cells and schistosomula as targets (Grezel et al. 1993). When compared to the background killing in the presence of day 0 sera and sera from control animals, pooled sera from DNA-immunized rats (day 42 to

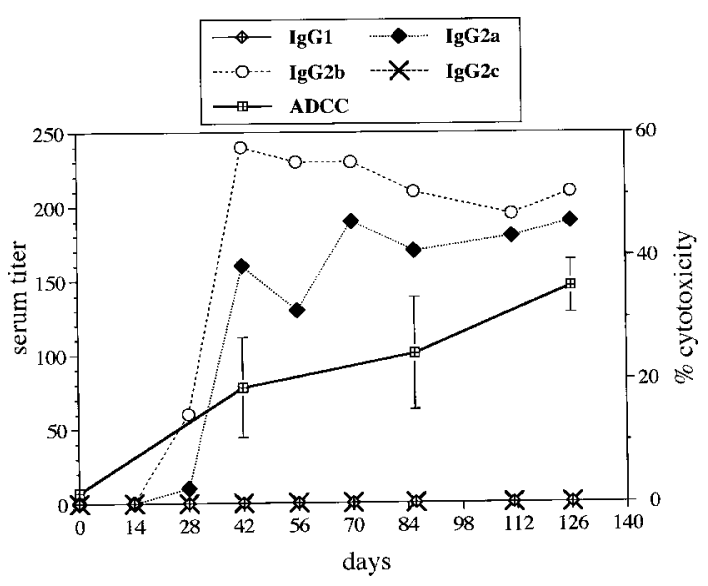

Fig. 3: antibody response and antibody-dependent cellular cytotoxicity toward schistosomula (ADCC) after intradermal immunization with plasmid DNA encoding Schistosoma mansoni $28 \mathrm{kDa}$ glutathione S-transferase. Rats were administered with $200 \mu \mathrm{g}$ of plasmid at days 0,14 and 28 by intradermal route. Specific anti Sm28GST IgG1, IgG2a, IgG2b and IgG2c titers in pooled sera were determined at different time points (ELISA), and reported as the reciprocal of the dilution giving an OD three times points after administration were tested with naive rat macrophages as effector cells. Results are expressed as the percentage of killed schistosomula (meand and SD of duplicate experiments) (Dupré et al. 1997).

day 126) were able to mediate the killing of schistosomula at significant levels $(\mathrm{p}<0.05)$. This $\mathrm{ADCC}$ activity was concomitant with the presence of specific antibodies and increased gradually with sera collected from day 42 to day 126 after the first immunization (Fig. 3).

Thus, intradermal DNA immunization with plasmid DNA encoding Sm28GST is able to induce a long-lasting specific antibody response at the systemic level against $S$. mansoni infection. Induced antibodies are able to mediate ADCC which is considered as a major protective mechanism involved in the reduction of worm burden. Moreover, the induction of protective immunity in the skin is particularly attractive for the control of $S$. mansoni infection since the skin is the first tissue encountered by the parasite which is thought to be more susceptible to the immune defences at this early stage than at later maturation stages. Interestingly, a strong and rapid (3 days) booster ef- 
fect was observed after infection of the immunized rats with cercariae indicating that native Sm28GST reactivated the specific antibody response. This phenomenon is unique considering that the booster effect observed after infestation of animals immunized with conventional or mucosal vaccines, appears 2 or 3 weeks after skin contact with cercariae (Mielcarek et al. 1997). When considering the duration of parasite migration through the skin (up to 3 to 4 days), it is conceivable that the secondary immune response was elicited at the skin level. This is supported by the fact that during penetration cercariae liberate several products including 28GST and that schistosomula express this antigen in the course of migration trough the skin (Porchet et al. 1994). Indeed, the immune reaction observed would happen within hours after cercariae penetration through the skin, before they acquire a masking coat of host molecules, both glycolipids and glycoproteins (Riveau \& Capron 1996). Even if the profile of the immune response induced in our model is probably of a Th1-like profile, which is recognised as a general feature of NAV immunization, a consistent ADCC activity was clearly developed by the sera. The detection of this activity, which could be considered as a major defence mechanism against schistosome larvae, could explain the consistent reduction of worm burden observed in rats during the preliminary protective experiments $(>60 \%)$.

\section{CONCLUDING REMARKS}

Although the identification of the definitive vaccine formulation for human use adapted to the field is far from the present approaches we are developing, these researches represent the necessary steps to get what we expect: a vaccine with a good efficacy in terms of appropriate immune response with long-lasting protection, a good adaptation to the epidemiological situation in afflicted areas, a good immunogenicity in all individuals, a crossspecificity of antigen formulation, an easy and appropriate delivery system, no early or delayed sideeffects, no disease-potentiating effects, and economic acceptability.

Our present results and consistent ones obtained in other laboratories around the world indicate that the prospects for an effective vaccine against schistosomiasis are very real. Definitively, the 28GST antigen is considered worldwide as a candidate molecule for such a vaccine, especially for its capacity to induce an anti-fecundity effect. Although high levels of protection can be induced by a vaccine including 28GST, it remains likely that MHC restriction of the immune response in outbred populations will necessitate either a manipulation of the immune response by selective epitopic presenta- tion, or the incorporation of other protective antigens in the definitive vaccine. The discovery that animals and humans develop partial immunity to new schistosome infection, focused attention to these mechanisms which the schistosome seems to deploy to make itself invisible to the host's immune system in acquiring host-derived macromolecules on its outer membrane. Interestingly, one of the effects of chemotherapy with praziquantel is to blister the surface skin of the schistosome, thereby penetrating the shield that makes it invisible to the host, and rendering it vulnerable to specific immune attack and destruction by the host effector cells. A combination of chemotherapy with a vaccine cocktail strategy could therefore well be the main hope for control of schistosomiasis.

However, trials of vaccine candidates in humans should be at first developed independently to combination, in terms of tolerance and immune reactivity to schistosome antigens. The recent knowledge on S. haematobium infection in human populations obtained from the development of epidemiological studies conducted under EEC auspices, and the results acquired from the research on experimental models of urinary schistosomiasis, give us the opportunity to define the parameters for vaccination in man with Sh28GST. Indeed, taking into account all information obtained recently, the effects on egg output and viability due to anti-fecundity immunity generated by vaccination with 28GST are sufficient to justify rapid progress to human trials. In that way, Phase I clinical trials of Sh28GST in conventional vaccine formulation (alum) took place in Europe in December 1997. Phase II has been already designed in three endemic countries for the following years. These trials will represent a major milestone in the achievement of the future vaccine against schistosomiasis.

\section{ACKNOWLEDGMENTS}

To Transgène for production and purification of recombinant Sm28GST. To G Renauld-Mongénie for providing BPGR60 and L Kremer for recombinant BCG.

\section{REFERENCES}

Auriault C, Gras-Masse H, Pierce RJ, Butterworth AE, Wolowczuck I, Capron M, Ouma JH, Balloul JM, Khalife J, Neyrinck JL, Tartar A, Koech D, Capron A 1990. Antibody response of Schistosoma mansoniinfected human subjects to the recombinant P28 glutathione-S-transferase and to synthetic peptides. $J$ Clin Microbiol 28: 1918-1924.

Balloul JM, Boulanger D, Sondermeyer P, Dreyer D, Capron M, Grzych JM, Pierce RJ, Carvallo D, Lecocq JP, Capron A 1987. Vaccination of baboons with a P28 antigen of Schistosoma mansoni expressed in Escherichia coli, p. 77-84. In AJ McInnes, Molecular Paradigms for Eradicating Helminthic 
Parasites, Liss, Alan R, Inc., New-York.

Balloul JM, Pierce RJ, Grzych JM, Capron A 1985. In vitro synthesis of a $28 \mathrm{kDa}$ antigen present on the surface of the schistosomulum of Schistosoma mansoni. Mol Biochem Parasitol 17: 105-114.

Balloul JM, Sondermeyer P, Dreyer D, Capron M, Grzych JM, Pierce RJ, Carvallo D, Lecocq JP, Capron A 1987. Molecular cloning of a protective antigen of schistosomes. Nature 326: 149-153.

Bouchara HO, Bashir MEN, Malik KHE, Muhktar MM, Trottein F, Capron A, Taylor MG 1993. Suppression of $S$. bovis egg production in cattle by vaccination with either glutathione S-transferase or keyhole limpet hemocyanin. Parasite Immunol 15: 383-390.

Boulanger D, Reid GDF, Sturrock RF, Wolowczuck I, Balloul JM, Grezel D, Pierce RJ, Otieno MF, Guerret S, Grimaud JA, Butterworth AE, Capron A 1991. Immunization of mice and baboons with the recombinant Sm28GST affects both worm viability and fecundity after experimental infection with Schistosoma mansoni. Parasite Immunol 13: 473-490.

Boulanger D, Warter A, Trottein F, Mauny F, Bremond P, Audibert F, Couret D, Kadri S, Godin C, Sellin E, Pierce RJ, Lecocq JP, Sellin B, Capron A 1995. Vaccination of patas monkeys experimentally infected with Schistosoma haematobium using a recombinant glutathione S-transferase clones from S. mansoni. Parasite Immunol 17: 361-369.

Bout D, Dupas H, Carlier Y, Afchain D, Capron A 1977. High resistance induced by young live bacillus Calmette-Guérin (BCG) to Schistosoma mansoni infection in mice. Ann Immunol 128C: 811-816.

Colditz GA, Brewer TF, Berkey CS, Wilson ME, Burdick E, Fineberg HV, Mosteller F 1994. Efficacy of BCG vaccine in the prevention of tuberculosis: metaanalysis of the published literature. JAMA 271: 698702.

De Bont J, Vercruysse J, Grzych JM, Meeus PFM, Capron A 1997. Potential of a recombinant Schistosoma bovis-derived glutahione S-transferase to protect cattles against experimental and natural $S$. mattheei infection. I. Parasitological results. Parasitology 115: 249-255.

Dupré L, Poulain-Godefroy O, Ban E, Ivanoff N, Mekranfar M, Schacht A-M, Capron A, Riveau G 1997. Intradermal immunization of rats with plasmid DNA encoding 28kDa glutathione S-transferase. Parasite Immunol 19: 503-513.

Fallon PG, Tao L-F, Ismail MM, Bennett JL 1996. Schistosome resistance to praziquantel: fact or artifact? Parasitol Today 12: 316-320.

Fynan EF, Webster RG, Fuller DH, Haynes JR, Santoro JC, Robinson HL 1993. DNA vaccines: protective immunizations by parenteral, mucosal and gene-gun inoculations. Proc Natl Acad Sci USA 90: 1147811482

Grezel D, Capron M, Grzych JM, Fontaine J, Lecocq JP, Capron A 1993. Protective immunity induced in rat schistosomiasis by a single dose of the Sm28GST recombinant antigen: effector mechanisms involving IgE and IgA antibodies. Eur J Immunol 23: 454-460. Grzych JM, Grezel D, Xu CB, Neyrinck JL, Capron M,
Ouma JH, Butterworth AE, Capron A 1993. IgA antibodies to a protective antigen in human schistosomiasis mansoni. J Immunol 150: 527-635.

Huygen K, Content J, Denis O, Montgomery DL, Yawman AM, Deck RR, DeWitt CM, Orme IM, Baldwin S, D'Sousa C, Drowart A, Lozes E, Vandenbussche P, Vooren J-PV, Liu MA, Ulmer JB 1996. Immunogenicity and protective efficacy of a tuberculosis DNA vaccine. Nat Med 2: 893-898.

Ismail MM, Taha SA, Farghaly AM, el Azony AS 1994. Laboratory induced resistance to praziquantel in experimental schistosomiasis. J Egypt Soc Parasitol 24: 685-695.

Ivanoff N, Phillips N, Schacht AM, Heydari C, Capron A, Riveau G 1996. Mucosal vaccination against schistosomiasis using liposome-associated Sm28kDa glutathione S-transferase. Vaccine 14: 1123-1131.

Khan CMA, Villarreal-Ramos B, Pierce RJ, Riveau G, de Hormaeche RD, McNeill H, Ali T, Fairweather N, Chatfield S, Capron A, Dougan G, Hormaeche CE 1994. Construction, expression, and immunogenicity of the Schistosoma mansoni P28 glutathione-S-transferase as a genetic fusion to tetanus toxin fragment $\mathrm{C}$ in a live Aro attenuated vaccine strain of Salmonella. Proc Natl Acad Sci USA 91: 11261-11265.

Kremer L, Riveau G, Baulard A, Capron A, Locht C 1996. Neutralizing antibody responses elicited in mice immunized with recombinant bacillus Calmette-Guérin producing the Schistosoma mansoni glutathione S-transferase. J Immunol 156: 4309-4317.

Ladel CH, Daugelat S, Kaufmann SHE 1995. Immune response to Mycobacterium bovis bacille Calmette Guérin infection in major histocompatibility complex class I- and II-deficient knock-out mice: contribution of CD4 and CD8 T cells to acquired resistance. Eur J Immunol 25: 377-384.

Lai WC, Bennett M, Johnston SA, Barry MA, Pakes SP 1995. Protection against Mycoplasma pulmonaris infection by genetic vaccination. DNA Cell Biol 14: 643-651.

Locht C, Bertin P, Menozzi FD, Renauld G 1993. The filamentous haemagglutinin, a multifaced adhesin produced by virulent Bordetella spp. Mol Microbiol 9: 653-660.

McNair A, Dissous C, Duvaux-Miret O, Capron A 1993. Cloning and characterization of the gene encoding the $28 \mathrm{kDa}$ glutathion S-transferase of Schistosoma mansoni. Gene 124: 245-249.

Mielcarek N, Cornette J, Schacht A-M, Pierce R, Locht C, Capron A, Riveau G 1997. Intranasal priming with recombinant Bordetella pertussis for the induction of a systemic immune response against a heterologous antigen. Infect Immun 65: 544-550.

Mielcarek N, Riveau G, Remou F, Antoine R, Capron A, Locht C 1998. Homologous and heterologous protection after single intranasal administration of live attenuated recombinant Bordetella pertussis. Nature Biotech 16: 454-457.

Mitchell GF 1989. Glutathione S-transferases - potential components of anti-schistosome vaccines? 
Parasitol Today 5: 34-37.

Mountford AP, Coulson PS, Pemberton RM, Smythies LE, Wilson RA 1992. The generation of interferongamma-producing $\mathrm{T}$ lymphocytes in skin-draining lymph nodes, and their recruitment to the lungs, is associated with protective immmunity to Schistosoma mansoni. Immunology 75: 250-256.

Pancré V, Wolowczuk I, Guerret S, Copin MC, Delanoye A, Capron A, Auriault C 1994. Protective effect of rSm28GST-specific T cells in schistosomiasis: role of gamma interferon. Infect Immun 62: 3723-3730.

Phillips NC, Gagné L, Ivanoff N, Riveau G 1996. Influence of phospholipid composition on antibody responses to liposome encapsulated protein and peptide antigens. Vaccine 14: 898-904.

Porchet E, McNair A, Caron A, Kusnierz JP, Zemzoumi K, Capron A 1994. Tissue expression of the Schistosoma mansoni $28 \mathrm{kDa}$ glutathione S-transferase. Parasitology 109: 565-572.

Renauld-Mongenie G, Mielcarek N, Cornette J, Schacht AM, Capron A, Riveau G, Locht C 1996. Induction of mucosal immune responses against a heterologous antigen fused to filamentous hemagglutinin after intranasal immunization with recombinant Bordetella pertussis. Proc Natl Acad Sci USA 93: 7944-7949.

Riveau GJ, Capron A 1996. Vaccination against schistosomiasis: concepts and strategies, p. 509-532. In SHE Kaufmann, Concepts in Vaccine Design, Walter de Gruyter and Co., Berlin, New York.

Stover CK, de la Cruz VF, Fuerst TR, Burlein JE, Benson LA, Bansal GP, Young JF, Lee MH, Hatfull GF, Snapper SB, Barletta RG, Jacobs WR, Bloom BR 1991. New use of BCG for recombinant vaccines. Nature 351: 456-460.

Taylor JB, Vidal A, Torpier G, Meyer DJ, Roitsch C, Balloul JM, Southan C, Sondermeyer P, Pemble S, Lecocq JP, Capron A, Ketterer B 1988. The gluthathione transferase activity and tissue distribu- tion of a cloned $\mathrm{Mr} 28 \mathrm{~K}$ protective antigen of Schistosoma mansoni. EMBO J 7: 465-472.

Trottein F, Godin C, Pierce RJ, Sellin B, Taylor MG, Gorrillot I, Sampaio SM, Lecocq JP, Capron A 1992a. Interspecies variation of schistosome $28 \mathrm{kDa}$ glutatione S -transferase. Mol Biochem Parasitol 54: 63-72.

Trottein FM, Vaney C, Bachet B, Pierce RJ, Colloc'h N, Lecocq JP, Capron A, Mormon JP 1992b. Crystallization and preliminary X-ray diffraction studies of a protective cloned $28 \mathrm{kDa}$ glutathione S-transferase from Schistosoma mansoni. J Mol Biol 224: 515518.

Ulmer JB, Donnelly JJ, Parker SE, Rhodes GH, Felgner PL, Dwarki VJ, Gromkowski SH, Deck RR, DeWitt CM, Friedman A, Hawe LA, Leander KR, Martinez D, Perry HC, Shiver JW, Montgomery DL, Liu MA 1993. Heterologous protection against influenza by injection of DNA encoding a viral protein. Science 259: 1745-1749.

Wang B, Boyer J, Srikantan V, Ugen K, Gilbert L, Phan C, Dang K, Merva M, Agadjanyan MG, Newman M, Carrano R, McCallus D, Coney L, Williams WV, Weiner DB 1995. Induction of humoral and cellular immune response to the human immunodeficiency type 1 virus in nonhuman primates by in vivo DNA inoculation. Virology 211: 102-112.

Xu CB, Verwaerde C, Gras-Masse H, Fontaine J, Bossus M, Trottein F, Wolowczuk I, Tartar A, Capron A 1993. Schistosoma mansoni 28-kDa glutathione Stransferase and immunity against parasite fecundity and egg viability. Role of the amino- and carboxylterminal domains. J Immunol 150: 940-949.

Xu C-B, Verwaerde C, Grzych J-M, Fontaine J, Capron A 1991. A monoclonal antibody blocking the Schistosoma mansoni $28-\mathrm{kDa}$ glutathione S-transferase activity reduces female worm fecundity and egg viability. Eur J Immunol 21: 1801-1807. 